\title{
Spinal cerebrospinal fluid leak in the context of pars interarticularis fracture
}

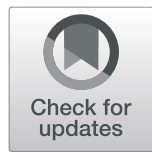

Tommy Lik Hang Chan ${ }^{1 *}$, Robert Cowan ${ }^{1}$, Nada Hindiyeh', Syed Hashmi², Bryan Lanzman² and lan Carroll ${ }^{3}$

\begin{abstract}
Background: Spinal cerebrospinal fluid (CSF) leak can lead to intracranial hypotension and is an important differential diagnosis to consider in patients with sudden-onset chronic daily headaches. Pars interarticularis (PI) fracture is a potential rare cause of suspected spinal CSF leak.

Methods: This is a retrospective case series of 6 patients with suspected spinal CSF leak evaluated between January 2016 and September 2019. All patients received a magnetic resonance imaging (MRI) of the brain with and without gadolinium, MRI whole spine and full spine computed tomography (CT) myelogram. Targeted epidural patches with fibrin sealant were performed. Treatment response at return visit (3 months post-patch) was documented.

Results: Six patients (4 females, 2 males) were diagnosed with a suspected spinal CSF leak and PI fracture. Mean age at the time of headache onset was 39 years old, and a range from 32 to 50 years old. Mean time to targeted epidural patches with fibrin sealant was 4.5 years. All 6 patients had PI fractures identified on CT myelogram and received targeted epidural patches with fibrin sealant at the site of the PI fracture. All patients had significant improvement in their headache intensity.

Conclusion: Our study highlights: 1) the importance of PI fracture as a possible culprit of suspected spinal CSF leak in patients with intracranial hypotension; 2) the added benefit of $\mathrm{CT}$ imaging for detecting bony abnormalities such as fractures in patients with intracranial hypotension; and 3) the successful treatment of suspected spinal CSF leak when targeting the fracture site.
\end{abstract}

Keywords: Spinal cerebrospinal fluid leak, Spinal CSF leak, Intracranial hypotension, Pars interarticularis fracture

\section{Background}

Spinal cerebrospinal fluid (CSF) leak can lead to intracranial hypotension and is an important differential diagnosis to consider in patients with sudden onset chronic daily headaches. This entity can often be confused with other chronic headache disorders, such as new daily persistent headache and chronic migraine. The most common clinical manifestation of a spinal CSF leak is orthostatic headache (worse upright) [1]. However, there is a wide variation of clinical presentation in headache arising from a spinal CSF leak including non-positional

\footnotetext{
* Correspondence: thchan@stanford.edu

'Division of Headache and Facial Pain, Department of Neurology \&

Neurological Sciences, Stanford University, Palo Alto, CA, USA

Full list of author information is available at the end of the article
}

headache [1-4], second half of the day headache [5], exertional headache [3, 6], cough headache [7], thunderclap headache [8-10], and paradoxical headache (in which symptoms are worse when supine) [11-15].

In addition to orthostatic headache, patients with spontaneous intracranial hypotension $(\mathrm{SIH})$ can experience a broad clinical spectrum of symptoms, including cochleovestibular dysfunction $[16,17]$, cranial nerve palsies, visual blurring, upper limb symptoms, encephalopathy, autonomic dysfunction, and cognitive dysfunction [18-20]. This is presumptively due to sagging of the brain causing significant traction, distortion or compression of anchoring and supporting structures [21]. Several imaging modalities have been utilized to aid in the diagnosis of spinal CSF leak including magnetic resonance

(c) The Author(s). 2020 Open Access This article is licensed under a Creative Commons Attribution 4.0 International License, which permits use, sharing, adaptation, distribution and reproduction in any medium or format, as long as you give appropriate credit to the original author(s) and the source, provide a link to the Creative Commons licence, and indicate if changes were made. The images or other third party material in this article are included in the article's Creative Commons licence, unless indicated otherwise in a credit line to the material. If material is not included in the article's Creative Commons licence and your intended use is not permitted by statutory regulation or exceeds the permitted use, you will need to obtain permission directly from the copyright holder. To view a copy of this licence, visit http://creativecommons.org/licenses/by/4.0/ The Creative Commons Public Domain Dedication waiver (http://creativecommons.org/publicdomain/zero/1.0/) applies to the data made available in this article, unless otherwise stated in a credit line to the data. 
imaging (MRI) of the brain with and without gadolinium, MRI whole spine, radioisotope cisternography, magnetic resonance myelogram, computed tomography (CT) myelogram or digital subtraction myelogram, each with proposed individual benefits and drawbacks [22, 23].

Spinal CSF leak is commonly precipitated by traumatic events such as motor vehicle accidents, sports injuries, and medical procedures such as dural or epidural punctures [22]. However, only $30 \%$ of patients with $\mathrm{SIH}$ can identify an inciting event or trauma, with the majority of patients unable to trace the onset of symptoms to any unusual circumstances at all [24]. SIH may arise in an area of a pre-existing dural sac weakness secondary to connective tissue disorders or spinal conditions such as herniated disc or spondylotic spurs [22]. However, there is no available medical literature highlighting osseous fracture as a potential cause of suspected spinal CSF leak, including pars interarticularis (PI) fracture. PI fracture is a stress fracture involving the posterior vertebral arch. This injury occurs in the lower lumbar region, most often at L5 and S1 [25]. Discovery of a PI fracture is often an incidental imaging finding in an asymptomatic patient or in an adolescent athlete involved in sports requiring repetitive lumbar loading in extension and rotation [26]. In this setting, patient may present with acute or insidious onset lower back pain. We suspect PI fracture can rarely be a potential cause of suspected spinal CSF leak. In this retrospective case series, we identified PI fractures in patients with suspected spinal CSF leak and their clinical outcomes were reported.

\section{Methods}

Six cases of suspected spinal CSF leak secondary to PI fracture were identified retrospectively. All patients were evaluated between January 2016 to September 2019 at the Stanford CSF leak headache clinic. All cases were presented at the neuroradiology/headache neurology CSF leak conference with headache specialists, anesthesiologists and neuroradiologists in attendance. All patients received an MRI of the brain with and without gadolinium, MRI whole spine and full spine CT myelogram. No bedside lumbar puncture was performed. These studies were interpreted by board-certified neuroradiologists. All targeted epidural patches with fibrin sealant were performed by a team member board-certified in Headache, Anesthesiology, and Pain Medicine (IC). Treatment response at return visit (3 months post-patch) was documented based on a pain intensity scale from 0 to 10,10 being the most severe. This study received IRB approval (eProtocol 52,298, IRB 61, Registration 4947) from Stanford University.

\section{Statistical analysis}

This is a descriptive case series study only, so no statistical analysis was utilized.

\section{Results}

Six patients (4 females and 2 males) had suspected spinal CSF leak based on their clinical and/or radiological findings. All 6 patients complained of daily unremitting orthostatic headaches. Patient 3, 4, and 5 had migraine features (throbbing/pounding, moderate to severe intensity, worse with activity, photophobia, phonophobia, and nausea) with their headaches. Patient 1, 2, and 6 had severe occipital pressure pain with their headaches. They had a number of concomitant symptoms including blurry vision, tinnitus, ear fullness, altered taste, vertigo, neck pain, interscapular pain, autonomic dysfunction and/or cognitive dysfunction (Table 1). Mean age at the time of onset of headache was 39 years old, with a range from 32 to 50 years old. Mean time to targeted epidural patches with fibrin sealant was 4.5 years. All 6 patients had limited therapeutic response to pharmacological treatment listed in Table 1. Four patients had an MRI brain reported as normal and 2 patients had radiological features suggestive of intracranial hypotension (Patient 1 and 2 had pachymeningeal enhancement [Fig. 1a, b], patient 2 had subdural collections [Fig. 1c]). All 6 patients had PI fracture identified on CT myelogram. Patient 1 and 6 recalled an inciting event (after hiking and after a mechanical fall respectively) with onset of headache within $24 \mathrm{~h}$. Patient 1 complained of lower back pain. Four patients had contrast nerve sleeves enhancement at multiple spinal levels and patient 1 had epidural fluid collection on CT myelogram. Opening pressure was not recorded in 5 patients and 1 patient (Patient 5 ) had an opening pressure measured at $18 \mathrm{~cm} \mathrm{H} 20$ from the CT myelogram. The mean number of interventions before targeted treatment at the PI fracture site was 3.8. The clinical and radiological characteristics for the 6 documented patients are included in Table 2, while treatment method and response are documented in Table 3. All 6 patients had an improvement (Greater than 50\% reduction) in their headache intensity at their return visit (3 months post-patch) documented based on a pain intensity scale from 0 to 10,10 being the most severe after treatment targeted at the PI fracture site (Table 3). All 6 patients indicated a subjective improvement of their concomitant symptoms and reported a reduction in their analgesics use. Patient 1 and 4 developed suspected rebound intracranial hypertension 6 months after treatment with reverse postural headache (worse when supine), improved with diuretics and/or carbonic anhydrase inhibitors.

\section{Case illustration (Patient 1)}

A 32-year-old male developed a severe positional headache following a hiking trip. The headache location was occipital in nature. He also complained of tinnitus, interscapular pain, lower back pain, autonomic dysfunction 
Table 1 Patient Medical History

\begin{tabular}{|c|c|c|c|}
\hline Patient & Past Medical History & Concomitant Symptoms & $\begin{array}{l}\text { Pharmacological } \\
\text { Treatments }\end{array}$ \\
\hline \multirow[t]{2}{*}{1} & \multirow[t]{2}{*}{ None } & \multirow{2}{*}{$\begin{array}{l}\text { Neck stiffness, tinnitus, interscapular pain, lower back pain, autonomic dysfunction and } \\
\text { anxiety }\end{array}$} & Ibuprofen \\
\hline & & & Oxycodone \\
\hline \multirow[t]{2}{*}{2} & \multirow[t]{2}{*}{ None } & \multirow[t]{2}{*}{ Blurry vision, tinnitus, ear fullness, vertigo and cognitive dysfunction } & Oxycodone \\
\hline & & & Ibuprofen \\
\hline \multirow[t]{3}{*}{3} & Ehlers-Danlos Syndrome & \multirow[t]{3}{*}{ Tinnitus, vertigo, neck pain, autonomic and cognitive dysfunction } & Sertraline \\
\hline & \multirow[t]{2}{*}{ Migraine } & & Sumatriptan \\
\hline & & & Naproxen \\
\hline \multirow[t]{3}{*}{4} & Depression & \multirow{3}{*}{$\begin{array}{l}\text { Blurry vision, neck pain, tinnitus, ear fullness, altered taste, interscapular pain, autonomic } \\
\text { and cognitive ysfunction }\end{array}$} & Amlodipine \\
\hline & Hypertension & & Amitriptyline \\
\hline & Migraine & & Naproxen \\
\hline \multirow[t]{2}{*}{5} & \multirow{2}{*}{$\begin{array}{l}\text { Prior C5/6 discectomy } \\
\text { Depression }\end{array}$} & \multirow{2}{*}{$\begin{array}{l}\text { Blurry vision, neck pain, tinnitus, ear fullness, altered taste, interscapular pain, autonomic } \\
\text { and cognitive dysfunction }\end{array}$} & Amitriptyline \\
\hline & & & Acetaminophen \\
\hline 6 & Corneal transplant & Neck pain, tinnitus, ear fullness, difficulty swallowing and cognitive dysfunction & Acetaminophen \\
\hline
\end{tabular}

and anxiety shortly after the onset of his orthostatic headache. Ibuprofen and oxycodone provided no relief. His past medical history was unremarkable. Neurological examination was unremarkable. MRI of the brain with and without gadolinium demonstrated diffuse pachymeningeal enhancement (Fig. 1a). Full spine CT myelogram revealed a ventral cervicothoracic epidural fluid collection extending from the mid cervical spine to approximately T8 (Fig. 2). He underwent 4 patches over a span of 2 years: 2 non-directed lumbar epidural blood patches, bilateral transforaminal T6-7 and right transforaminal T10-11 epidural blood patches with fibrin sealant ( $3 \mathrm{ml}$ each site), left paramedian $\mathrm{C} 7-\mathrm{T} 1$ and right T2-T3 paramedian interlaminar blood patches with catheters threaded under fluoroscopic guidance to the ventral epidural space $(10 \mathrm{ml}$ and $5 \mathrm{ml}$ respectively). The
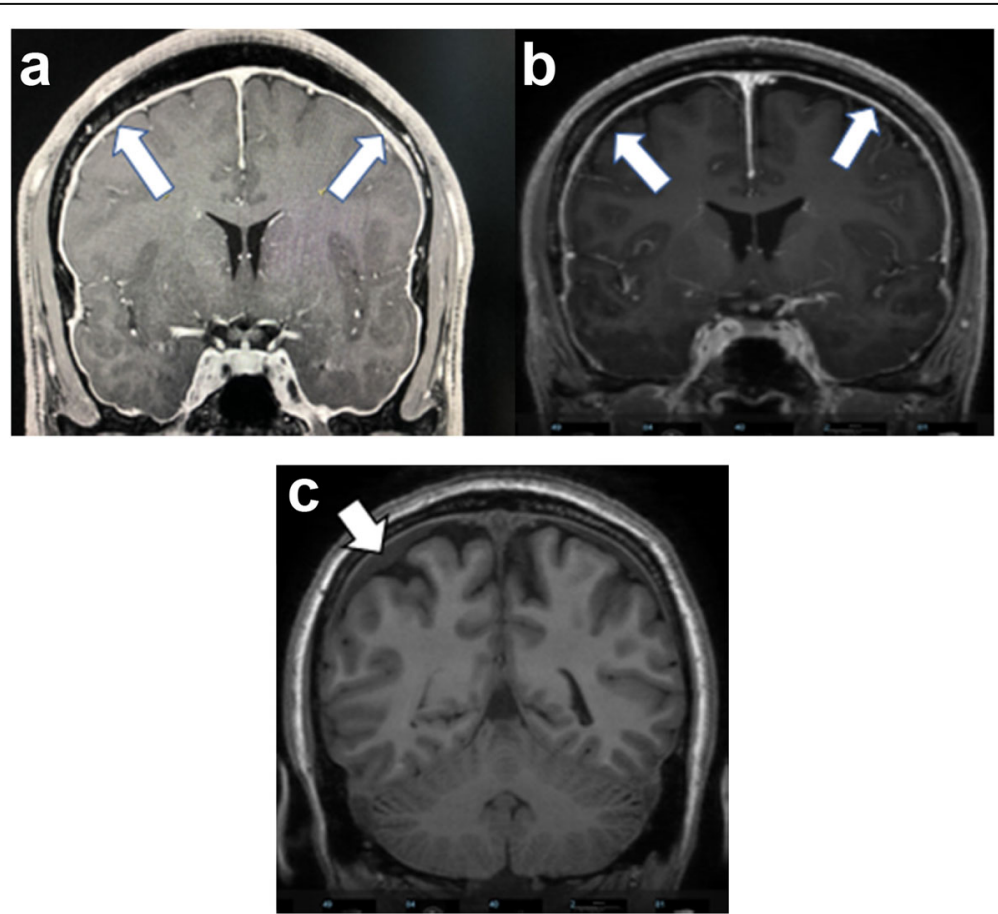

Fig. 1 a Patient 1 b Patient 2: Magnetic Resonance Imaging with gadolinium (Coronal T1 Spoiled Recalled Gradient-Echo) demonstrated diffuse pachymeningeal enhancement (arrows), a feature of intracranial hypotension. c: Patient 2: Magnetic Resonance Imaging (Coronal T1) demonstrated subdural collections (arrow), a feature of intracranial hypotension 
Table 2 Patient Characteristics

\begin{tabular}{|c|c|c|c|c|c|c|c|}
\hline $\begin{array}{l}\text { Patient \# } \\
\text { (Age } \\
\text { Gender) } \\
\end{array}$ & $\begin{array}{l}\text { Age } \\
\text { of } \\
\text { onset }\end{array}$ & $\begin{array}{l}\text { Inciting } \\
\text { event }\end{array}$ & $\begin{array}{l}\text { Orthostatic } \\
\text { headache (Worse } \\
\text { upright) }\end{array}$ & $\begin{array}{l}\text { MRI head (with } \\
\text { and without } \\
\text { gadolinium) }\end{array}$ & MRI spine & CT myelogram & $\begin{array}{l}\text { Previous } \\
\text { treatment }^{\mathrm{a}} \text { (\# } \\
\text { of patches) }\end{array}$ \\
\hline \multirow[t]{3}{*}{$1(35 \mathrm{M})$} & \multirow[t]{3}{*}{32} & \multirow{3}{*}{$\begin{array}{l}\text { Post- } \\
\text { hiking }\end{array}$} & \multirow[t]{3}{*}{ Yes } & \multirow{3}{*}{$\begin{array}{l}\text { Diffuse } \\
\text { pachymeningeal } \\
\text { enhancement }\end{array}$} & \multirow{2}{*}{$\begin{array}{l}\text { Central disc } \\
\text { protrusion at } \mathrm{T} 7 / 8, \\
\mathrm{~T} 11 / 12\end{array}$} & Bilateral L5 PI \# & \multirow[t]{3}{*}{4} \\
\hline & & & & & & \multirow[t]{2}{*}{$\begin{array}{l}\text { Diffuse epidural fluid collection in the } \\
\text { whole spine }\end{array}$} & \\
\hline & & & & & $\begin{array}{l}\text { Epidural fluid } \\
\text { collection extending } \\
\text { from L1-L5 }\end{array}$ & & \\
\hline \multirow[t]{4}{*}{$2(52 F)$} & \multirow[t]{4}{*}{50} & \multirow[t]{4}{*}{ None } & \multirow[t]{4}{*}{ Yes } & \multirow{2}{*}{$\begin{array}{l}\text { Diffuse } \\
\text { pachymeningeal } \\
\text { enhancement }\end{array}$} & \multirow{4}{*}{$\begin{array}{l}\text { Severe grade } 3\llcorner 4 / 5 \\
\text { spondylolisthesis }\end{array}$} & Bilateral L4 PI \# & \multirow[t]{4}{*}{3} \\
\hline & & & & & & $\llcorner 4 / 5$ anterolisthesis & \\
\hline & & & & \multirow[t]{2}{*}{$\begin{array}{l}\text { Subdural } \\
\text { collections }\end{array}$} & & $\begin{array}{l}\text { Mildly prominent perineural spaces at } \\
\text { bilateral C7-T1, right } T 7 / 8, T 8 / 9 \text {, bilat- } \\
\text { eral T9/10 }\end{array}$ & \\
\hline & & & & & & Small left S2 perineural cyst & \\
\hline \multirow[t]{3}{*}{3 (38F) } & \multirow[t]{3}{*}{34} & \multirow[t]{3}{*}{ None } & \multirow[t]{3}{*}{ Yes } & \multirow[t]{3}{*}{ Normal } & \multirow{3}{*}{$\begin{array}{l}\text { Mild degenerative } \\
\text { changes in the } C \text { and } \\
\text { L spine }\end{array}$} & Bilateral L5 PI \# & \multirow[t]{3}{*}{4} \\
\hline & & & & & & Multi-disc degeneration from C3-C6 & \\
\hline & & & & & & $\begin{array}{l}\text { Small amount of contrast seen in } \\
\text { multiple perineural sleeves } \\
\text { throughout the spine }\end{array}$ & \\
\hline \multirow[t]{4}{*}{$4(49 F)$} & \multirow[t]{4}{*}{39} & \multirow[t]{4}{*}{ None } & \multirow[t]{4}{*}{ Yes } & \multirow[t]{4}{*}{ Normal } & \multirow{2}{*}{$\begin{array}{l}\mathrm{C} 3 / 4, \mathrm{C} 4 / 5, \mathrm{C} 6 / 7 \text { disc } \\
\text { bulges }\end{array}$} & Bilateral L3 PI \# & \multirow[t]{4}{*}{2} \\
\hline & & & & & & Grade 1 L3/4 anterolisthesis & \\
\hline & & & & & L3/4 anterolisthesis & Nerve root sleeve opacification at the & \\
\hline & & & & & S1 Tarlov cyst & $\begin{array}{l}\text { left } \mathrm{C} 6 / /, \mathrm{C} / / 1 \mathrm{1}, \mathrm{LS} / \mathrm{S} 1 \text { and right } \mathrm{I12/} \\
\mathrm{L} 1\end{array}$ & \\
\hline \multirow[t]{2}{*}{5 (38F) } & \multirow[t]{2}{*}{34} & \multirow[t]{2}{*}{ None } & \multirow[t]{2}{*}{ Yes } & \multirow[t]{2}{*}{ Normal } & \multirow{2}{*}{$\begin{array}{l}\text { Prior discectomy at } \\
\text { C5/6 }\end{array}$} & S1 PI \# (right) & 3 \\
\hline & & & & & & $\begin{array}{l}\text { Bilateral nerve root sleeves at } C 5 / 6 \text {, } \\
C 6 / 7, C 7 / T 1, T 7 / 8, T 9 / 10, T 10 / 11 \text { and } \\
\text { all L levels }\end{array}$ & \\
\hline $6(49 M)$ & 45 & Fall & Yes & Normal & Normal & Bilateral L5 PI \# & 7 \\
\hline & & & & & & $\begin{array}{l}\text { Calcified osteophyte on left L5/S1 } \\
\text { facet join }\end{array}$ & \\
\hline
\end{tabular}

C Cervical T Thoracic L Lumbar S Sacral PI \#: Pars Interarticularis fracture

${ }^{a}$ All patients received conservative treatment plus a combination of the following: blind epidural blood patches, targeted blood patches and/or fibrin sealant

2 non-directed lumbar epidural blood patches provided transient and mild relief, but the subsequent 2 targeted patches provided no relief. Finally, the bilateral L5 PI fracture site (Fig. 3) was targeted with bilateral paramedian L4-5 and right paramedian L5-S1 epidural patches with fibrin sealant ( $3 \mathrm{ml}$ each site). In contrast with his previous patches, he noted resolution of his orthostatic headache with pain intensity dropped from 3 to 0 upright, on a scale of 0 to 10,10 being the most severe at his return visit (3 months post-patch). He discontinued his ibuprofen and oxycodone intake completely. He later returned to his full-time employment with minimal concomitant symptoms.

\section{Discussion}

All 6 patients suffered from chronic daily headaches and were diagnosed with suspected spinal CSF leak based on their clinical and/or radiological findings. Spinal CSF leak may resolve spontaneously or through conservative measures such as bed rest, oral hydration, generous caffeine intake and use of an abdominal binder [22, 23]; however, this was not seen in our patients. They did not respond to pharmacological treatment, conservative measures and failed multiple interventions including non-directed epidural blood patches and epidural patches targeted at levels outside of the PI fracture site, such as at the level of the contrast enhanced nerve sleeves and extradural collection. This highlights that in many cases of spinal CSF leak, it is imperative to identify the site of spinal CSF leak for targeted treatment with epidural patches to maximize response rate [23]. These cases highlight the difficulty in successfully identifying a target site.

The exact location of spinal CSF leak is often unknown. MRI brain may suggest signs of intracranial hypotension (subdural collections, pachymeningeal enhancement, venous engorgement, pituitary hyperemia and brain sagging), but these have no localizing value 
Table 3 Treatment Response

\begin{tabular}{|c|c|c|c|}
\hline \multirow[t]{2}{*}{ Patient } & \multirow{2}{*}{$\begin{array}{l}\text { Treatment method } \\
\text { (epidural patch with } \\
\text { fibrin sealant, paramedian } \\
\text { approach) }{ }^{\text {a }}\end{array}$} & \multicolumn{2}{|c|}{ Treatment response } \\
\hline & & Pre-treatment ${ }^{\mathbf{b}}$ & Post-treatment ${ }^{\mathbf{b}}$ (3 months post-patch) \\
\hline \multirow[t]{2}{*}{ 1a) } & Bilateral $L 4 / L 5$, right $L 5 / S 1$ & Upright: 3 & Upright: 0 \\
\hline & & Supine: 2 & Supine: 0 \\
\hline \multirow[t]{2}{*}{2} & Bilateral L4/L5 & Upright: 8 & Upright: 4 \\
\hline & & Supine: 2 & Supine: 1 \\
\hline \multirow[t]{2}{*}{3} & Bilateral L4/L5, left L5/S1 & Upright: 8 & Upright: 2 \\
\hline & & Supine: 0 & Supine: 0 \\
\hline \multirow[t]{2}{*}{ 4b) } & Bilateral L3/4 & Upright: 8 & Upright: 4 \\
\hline & & Supine: 4 & Supine: 2 \\
\hline \multirow[t]{2}{*}{5} & Right $L 4 / L 5$, right $L 5 / L 6$ & Upright: 7 & Upright: 3 \\
\hline & & Supine: 0 & Supine: 0 \\
\hline \multirow[t]{2}{*}{6} & Bilateral L5/S1 & Upright: 4 & Upright: 1 \\
\hline & & Supine: 3 & Supine: 0 \\
\hline
\end{tabular}

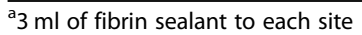

${ }^{\mathrm{b}}$ Pain intensity scale: $0-10,10$ being the most severe

a) At 6 months - suspected rebound intracranial hypertension managed with acetazolamide $250 \mathrm{mg}$ twice daily

b) At 6 months - suspected rebound intracranial hypertension managed with amiloride $10 \mathrm{mg}$ and furosemide $60 \mathrm{mg}$ daily

[23]. Spinal imaging such as MRI or CT myelogram can confirm a leak based on contrast in the extradural space or nerve sleeves, but may be falsely localizing [27]. Our patients had targeted low volume $(3 \mathrm{ml}$ each site) epidural patches with fibrin sealant at the site of the PI fractures with significant treatment response (Greater than $50 \%$ reduction in pain intensity) at their 3 month return visit, which suggests the PI fractures may be the culprit for their suspected spinal CSF leak. Previous reports have demonstrated intracranial hypotension or pseudomeningocele as potential complications from other orthopedic injuries including spondylolisthesis and

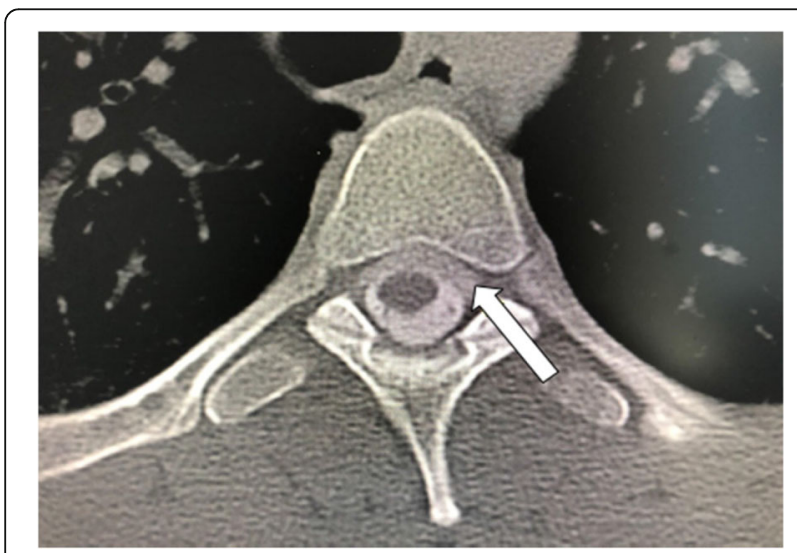

Fig. 2 Computed Tomography Myelogram (axial view) demonstrated a ventral cervicothoracic epidural CSF collection (arrow) extending from the mid cervical spine to mid thoracic level (Patient 1) vertebroplasty $[28,29]$. PI fractures were detected from the CT myelogram and were missed on the MRI spine in 5 out of the 6 patients. Our cases illustrate an added advantage of CT myelogram in the workup of suspected spinal CSF leak for osseous pathology [30].

Patient 1 demonstrated a transient and mild relief from his non-targeted lumbar epidural patches, which suggests a possibility that prior treatments were coincidentally injected at or near the site of PI fracture since the lumbar region is often a standard location for non-directed epidural blood patches. Limited information was available from chart review on the other patients' prior treatment response.

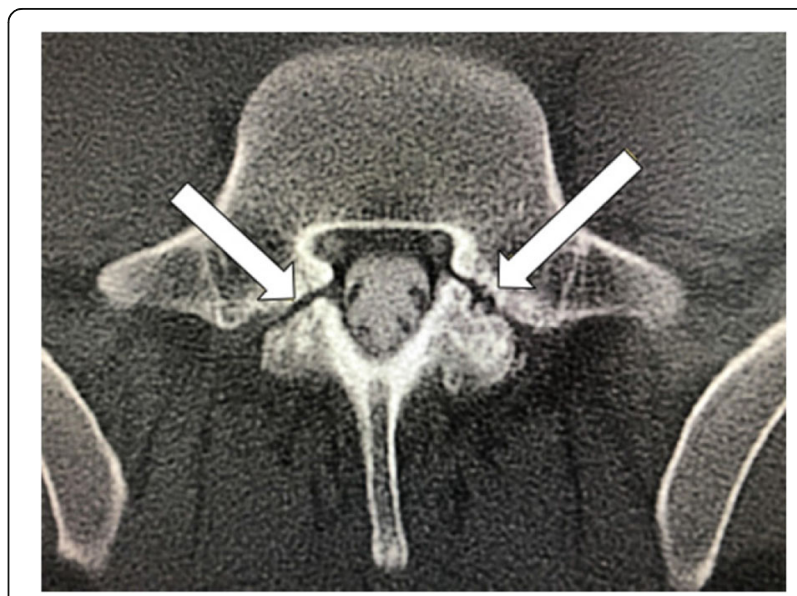

Fig. 3 Computed Tomography Myelogram (axial view) demonstrated bilateral L5 pars interarticularis fractures (arrows) (Patient 1) 
Patients 1 and 4 developed suspected rebound intracranial hypertension 6 months post-patch based on a change in their headache characteristics (headache worse lying supine). This information was relayed to our center from their primary providers. This illustrates a potential risk of spinal CSF leak treatment long term. Our patients had a prolonged clinical course before the PI fracture was identified as the suspected leak site. It is possible that contributed to an increased risk of rebound intracranial hypertension [31].

As for the PI fracture, the treatment is usually nonsurgical (rest and bracing). Surgery (laminectomy or posterior lumbar fusion) may be required if symptoms persist or remain bothersome [25]. Patient 1 complained of lower back pain, which could be a direct symptom of PI fracture, however his subjective improvement after the patch argued against the PI fracture being the cause and lower back pain is not an uncommon symptom in $\mathrm{SIH}$ [20].

\section{Limitations}

Some limitations were seen with this study: Two out of the 6 patients (Patient 1 and 2) met the diagnostic criteria of "headache attributed to low CSF pressure" as per the International Classification of Headache Disorders Third Edition [32]. The other 4 patients had suspected CSF leak based on supportive clinical and radiological findings, such as orthostatic headaches, enhancing nerve sleeves and/or favorable response to treatment. All cases were presented at the neuroradiology/headache neurology CSF leak conference and the diagnosis of suspected CSF leak was agreed upon a panel of headache specialists, anesthesiologists and neuroradiologists. Opening pressure was not measured in 5 patients and patient 5 had a normal opening pressure recorded [33]. Certainly, a detection of CSF pressure $<6 \mathrm{~cm} \mathrm{H} 2 \mathrm{O}$ supports the diagnosis of CSF leak, however, it is not uncommon to have a normal opening pressure with CSF leak, especially in chronic CSF leak patients. A normal opening pressure does not rule out a CSF leak [23]. All patients reported subjective improvement with their concomitant symptoms at their return visit, but not quantified. Long term follow-up (beyond 3 months) data are not available since our center is a tertiary referral center and our patients returned back to their primary and referring providers for subsequent follow-up. This is a retrospective case series limited by lack of control subjects and small population size. It is also subject to selection and information bias.

\section{Conclusion}

The diagnosis and management of spinal CSF leak causing $\mathrm{SIH}$ remains a challenge, especially in cases where the site of suspected CSF leak is difficult to detect. There are limitations to each imaging modality and often a combination is required to confirm and localize a CSF leak. Our study highlights: 1) the importance of PI fracture as a possible culprit of suspected spinal CSF leak in patients with intracranial hypotension; 2) the added benefit of $\mathrm{CT}$ imaging for detecting bony abnormalities such as fractures in patients with intracranial hypotension; and 3) the successful treatment of suspected spinal CSF leak when targeting the fracture site. If no clinical improvement is observed after adequate conservative measures (bed rest, oral hydration, generous caffeine intake and use of an abdominal binder) or non-targeted epidural patches in the context of a nonlocalizing spinal CSF leak, further testing may be warranted to explore an osseous pathology, such as occult fractures. No conclusions can be drawn regarding the frequency with which PI fractures are complicated by CSF leaks. Future research in a larger cohort of patients is required to explore the likelihood of detecting PI fracture in patients with non-localizing spinal CSF leak and to identify any risk factors associated with both PI fracture and spinal CSF leak. Long term follow-up data are required to explore the effectiveness and potential complication (i.e rebound intracranial hypertension) from targeted patches to the fracture site.

\section{Abbreviations \\ CSF: Cerebrospinal Fluid; CT: Computed Tomography; MRI: Magnetic Resonance Imaging; PI: Pars Interarticularis; SIH: Spontaneous Intracranial Hypotension}

\section{Acknowledgements}

Not Applicable.

\section{Authors' contributions}

TLHC wrote the manuscript. $\mathrm{RC}$ and $\mathrm{NH}$ reviewed and edited the manuscript. $\mathrm{SH}$ and $\mathrm{BL}$ obtained and interpreted the images. IC examined, performed the targeted blood patches and reviewed the manuscript. All authors read and approved the final version of the manuscript.

\section{Funding}

No funding was received for this study.

\section{Availability of data and materials}

The material analyzed during the current study are available from the corresponding author on reasonable request. Permission was obtained to access the patient data and the data was de-identified upon data collection.

\section{Ethics approval and consent to participate}

This study received ethics approval from the Institutional Review Board at Stanford University - Panel on Medical Human Subjects. eProtocol\#: 52298, IRB 61, Registration 4947.

Consent for publication

Written consent for publication was obtained from each patient.

\section{Competing interests}

The authors have no conflicts of interest (financial or non-financial) to disclose relevant to this study.

\section{Author details}

${ }^{1}$ Division of Headache and Facial Pain, Department of Neurology \& Neurological Sciences, Stanford University, Palo Alto, CA, USA. ²Department of Rad/Neuroimaging and Neurointervention, Stanford University, Palo Alto, CA, USA. ${ }^{3}$ Department of Anesthesia, Stanford University, Palo Alto, CA, USA. 
Received: 18 February 2020 Accepted: 21 April 2020

Published online: 29 April 2020

\section{References}

1. Mea E, Chiapparini L, Savoiardo M, Franzini A, Bussone G, Leone M. Clinical features and outcomes in spontaneous intracranial hypotension: a survey of 90 consecutive patients. Neurol Sci. 2009;30(Suppl 1):S11-3.

2. Ferrante E, Savino A. Nonpostural headache by spontaneous intracranial hypotension. Headache. 2003;43(2):127-9.

3. Wang S-J, Fuh J-L. Exertional but not postural headache resulting from spontaneous intracranial hypotension. Acta Neurol Taiwanica. 2005;14(1):367.

4. Schievink WI, Smith KA. Nonpositional headache caused by spontaneous intracranial hypotension. Neurology. 1998;51(6):1768-9.

5. Leep Hunderfund AN, Mokri B. Second-half-of-the-day headache as a manifestation of spontaneous CSF leak. J Neurol. 2012;259(2):306-10.

6. Mokri B. Spontaneous CSF leaks mimicking benign exertional headaches. Cephalalgia. 2002;22(10):780-3.

7. Evans RW, Boes CJ. Spontaneous low cerebrospinal fluid pressure syndrome can mimic primary cough headache. Headache. 2005;45(4):374-7.

8. Schievink WI, Wijdicks EF, Meyer FB, Sonntag VK. Spontaneous intracranial hypotension mimicking aneurysmal subarachnoid hemorrhage. Neurosurgery. 2001;48(3):513-6 discussion 516-7.

9. Famularo G, Minisola G, Gigli R. Thunderclap headache and spontaneous intracranial hypotension. Headache. 2005;45(4):392-3 author reply 393

10. Ferrante E, Savino A. Thunderclap headache caused by spontaneous intracranial hypotension. Neurol Sci. 2005;26(Suppl 2):s155-7.

11. Schievink WI, Chu RM, Maya MM, Johnson JP, Cohen HCM. Spinal manifestations of spontaneous intracranial hypotension. J Neurosurg Spine. 2013;18(1):96-101.

12. Mokri B, Aksamit AJ, Atkinson JLD. Paradoxical postural headaches in cerebrospinal fluid leaks. Cephalalgia. 2004;24(10):883-7.

13. Lupo I, Salemi G, Fierro B, Brighina F, Daniele O, Caronia A, et al. Headache in cerebrospinal fluid volume depletion syndrome: a case report. Funct Neurol. 2006;21(1):43-6.

14. Liu H, Kaye A, Comarda N, Li M. Paradoxical postural cerebrospinal fluid leak-induced headache: report of two cases. J Clin Anesth. 2008;20(5):383-5.

15. Liu H, Kalarickal PL, Rosinia F. A case of paradoxical presentation of postural postdural puncture headache. J Clin Anesth. 2012;24(3):255-6.

16. Isildak H, Albayram S, Isildak H. Spontaneous intracranial hypotension syndrome accompanied by bilateral hearing loss and venous engorgement in the internal acoustic canal and positional change of audiography. J Craniofac Surg. 2010;21(1):165-7.

17. Srimanee D, Pasutharnchat N, Phanthumchinda K. Bilateral subdural hematomas and hearing disturbances caused by spontaneous intracranial hypotension. J Med Assoc Thail. 2009;92(11):1538-43.

18. Amemiya S, Takahashi K, Mima T, Yoshioka N, Miki S, Ohtomo K. Reversible alterations of the neuronal activity in spontaneous intracranial hypotension. Cephalalgia. 2016;36(2):162-71.

19. Nakano M, Umehara F. Liquorrhea with multiple subdural hematomas causing reversible prospagnosia. Rinsho Shinkeigaku. 2012;52(2):96-101.

20. Capizzano AA, Lai L, Kim J, Rizzo M, Gray L, Smoot MK, et al. Atypical presentations of intracranial hypotension: comparison with classic Spontaneous intracranial hypotension. AJNR Am J Neuroradiol. 2016;37(7): 1256-61.

21. Mokri B. Spontaneous low pressure, low CSF volume headaches: spontaneous CSF leaks. Headache. 2013;53(7):1034-53.

22. Mokri B, Spontaneous CSF. Leaks: low CSF volume syndromes. Neurol Clin. 2014;32(2):397-422.

23. Schievink WI. Spontaneous spinal cerebrospinal fluid leaks and intracranial hypotension. JAMA. 2006;295(19):2286-96.

24. Schievink WI, Louy C. Precipitating factors of spontaneous spinal CSF leaks and intracranial hypotension. Neurology. 2007;69(7):700-2.

25. Mansfield JT, Wroten M. Pars Interarticularis Defect. In: StatPearls. Treasure Island (FL): StatPearls Publishing; 2019.

26. Cavalier R, Herman MJ, Cheung EV, Pizzutillo PD. Spondylolysis and spondylolisthesis in children and adolescents: I. diagnosis, natural history, and nonsurgical management. J Am Acad Orthop Surg. 2006;14(7):417-24.

27. Schievink WI, Maya MM, Chu RM, Moser FG. False localizing sign of cervicothoracic CSF leak in spontaneous intracranial hypotension. Neurology. 2015; 84(24):2445-8.
28. Chen Y-W, Tseng P-T, Tsui H-W, Hsu S-P, Kuo H-C. Intracranial hypotension as a rare complication of Vertebroplasty: a case report. Acta Neurol Taiwanica. 2015;24(3):97-101.

29. Novais G, Ratilal B, Pappamikail L, Branco P, Reis N. Spontaneous pseudomeningocele associated with lumbar spondylolisthesis: a case report and review of the literature. Surg Neurol Int. 2017;8:221.

30. Mokri B. Spontaneous Intracranial Hypotension. Continuum. 2015;21(4 Headache):1086-108.

31. Schievink WI, Maya MM, Jean-Pierre S, Moser FG, Nuño M, Pressman BD. Rebound high-pressure headache after treatment of spontaneous intracranial hypotension: MRV study. Neurol Clin Pract. 2019;9(2):93-100.

32. Headache Classification Committee of the International Headache Society (IHS). The International Classification of Headache Disorders, 3rd edition. Cephalalgia. 2018;38(1):1-211.

33. Whiteley W, Al-Shahi R, Warlow CP, Zeidler M, Lueck CJ. CSF opening pressure: reference interval and the effect of body mass index. Neurology. 2006;67(9):1690-1.

\section{Publisher's Note}

Springer Nature remains neutral with regard to jurisdictional claims in published maps and institutional affiliations.

\section{Ready to submit your research? Choose BMC and benefit from:}

- fast, convenient online submission

- thorough peer review by experienced researchers in your field

- rapid publication on acceptance

- support for research data, including large and complex data types

- gold Open Access which fosters wider collaboration and increased citations

- maximum visibility for your research: over $100 \mathrm{M}$ website views per year

At BMC, research is always in progress.

Learn more biomedcentral.com/submissions 